\title{
Some Formability Aspects of High Strength Steel and of Consisting Tailor Welded Blanks
}

\author{
Gábor J. BÉRES, ${ }^{1}$ Ferenc VÉGVÁRI, ${ }^{2}$ József DANYI ${ }^{3}$ \\ John von Neumann University, GAMF Faculty of Engineering and Computer Science, Department of Inno- \\ vative Vehicles and Materials, Kecskemét, Hungary \\ ${ }^{1}$ beres.gabor@gamf.uni-neumann.hu \\ ${ }^{2}$ vegvari.ferenc@gamf.uni-neumann.hu \\ 3 danyi.jozsef@gamf.uni-neumann.hu
}

\begin{abstract}
In recent years, the demand for a reduction in pollutant emission has become extremely important in the vehicle industry. It can be achieved through fuel consumption reduction, which is a direct function of the vehicle's weight. Nowadays weight is widely controlled by the use of advanced- and ultra-high strength steels (AHSS and UHSS) in vehicle body construction. With the application of such steel sheets as chassis elements, crashworthiness can be maintained next to reduced sheet thicknesses, too. In this paper, the deep-drawability and springback after V-die bending is monitored for three types of AHSS grades, namely DP600, DP800 and DP1000 materials. The investigations are extended to tailor welded blanks (TWBs), made by the aforementioned steels coupled with a cold rolled steel sheet (DC04). Our results show that deep-drawability reduces with both the increase in strength and the increase in strength difference between the components in the TWBs. Furthermore, the higher strength is shown to cause higher spring-back. The TWBs have unique springback behavior around the weld line.
\end{abstract}

Keywords: high strength steels, tailor welded blanks, deep-drawability, springback.

\section{Introduction}

Advanced high strength steels are widely used as body-in-white elements in the automotive industry, however, parts made by welded blanks are no longer uncommon. This reflects the aim of achieving idealized material distribution within the chassis. Since the elements' destination is a function of the location, the principle of the best material to the best place can be fulfilled also within a piece part if tailor welded blanks are used. At the same time, the different properties in such a complex blank can lead to different problems during the manufacturing processes, such as dimensional accuracy and unique failure modes [1].

Manufacturing using high strength steels can basically raises formability problems. Figure 1. shows that an increase in strength is accompa-nied by a reduction in formability [2].
In our work we focus on the deep-drawability and spring-back of three types of AHSS grades in the frames of a research project jointly with the Department of Mechanical Technologies at the University of Miskolc. This paper gives a brief insight

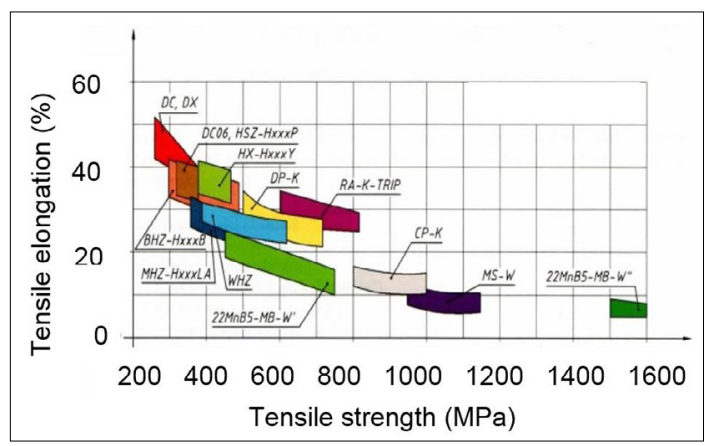

Figure 1. The relation of the strength and formability (through elongation) of todays' automotive steel sheets. 
into the experimental formability behaviour of dual phase steel sheets, furthermore the question of TWBs is also discussed if such materials are coupled with a cold rolled quality, namely with the DC04 sheet.

\section{Investigated materials}

The applied materials were three types of commercial, non-covered dual phase steels, Docol DP600, DP800 and DP1000 as well as a cold rolled steel grade, DC04. The last one is specially recommended for deep-drawing [3]. The DP abbreviation refers to the dual phase microstructure of the material, in which the soft ferrite and the hard martensitic phases together provide the high strength and the relative good formability [4]. The basic mechanical properties (yield strength, ultimate tensile strength, uniform- and total elongation) are listed in Table 1 . The tensile experiments were carried out in accordance with the MSZ EN ISO 6892 standard requirement at room temperature, on three parallel specimens. The sheets had $1 \mathrm{~mm}$ thickness $(t)$ uniformly.

Table 1. The basic mechanical properties of the applied materials.

\begin{tabular}{|l|c|c|c|c|}
\hline & $\begin{array}{c}\mathbf{R}_{\text {p0,2 }} \\
\text { (MPa) }\end{array}$ & $\begin{array}{c}\mathbf{R}_{\mathbf{m}} \\
\text { (MPa) }\end{array}$ & $\begin{array}{c}\mathbf{A}_{\mathrm{g}} \\
\mathbf{( \% )}\end{array}$ & $\begin{array}{c}\mathbf{A}_{80} \\
\mathbf{( \% )}\end{array}$ \\
\hline DC04 & 238 & 336 & 22.6 & 37.9 \\
\hline DP600 & 444 & 656 & 13.6 & 20.6 \\
\hline DP800 & 570 & 789 & 10.8 & 16.0 \\
\hline DP1000 & 758 & 1099 & 7.0 & 10.6 \\
\hline
\end{tabular}

\section{Investigation of springback after free bending}

It is well known that the bending angle changes following the bending tools release in a bending process, i.e. in the unloading stage. On one hand, this is caused by the elastic region near to the natural axis, which takes an elastic moment in the opposite direction to the bending. On the other hand, the total strain is the sum of the elastic and plastic strains, thus the elastic proportion tries to return the workpiece into the initial geometry [5]. As a result, the extent of the springback $(\beta)$ is primarily influenced by the strength, the elastic modulus and the thickness of the material, as well as the bending geometry, such as punch corner $(r)$ radius and bending angle [6, 7, 8, 9]. For the most comprehensive investigations of these factors, different grades of DP steels were applied with different punch corner radiuses, in this study. The bending investigations were performed on three parallel workpieces with constant $20 \mathrm{~mm} / \mathrm{min}$ stroke by an AMADA HFE 50-20 CNC machine (Figure 2.).

The side view sketch of the bending tools (punch and V-die) can be seen in Figure 3. Using $3 \mathrm{~mm}$ and $5 \mathrm{~mm}$ punch corner radiuses, different $r / t$ (punch corner radius/sheet thickness) ratios could be obtained during the experiments. All the samples were bent to $90^{\circ}$, which was controlled by the punch motion.

Figure 4. shows the measurement results of the base materials' mean springback angles, at 3 and at $5 r / t$ ratios. The indicated data points were determined on the edges of the sheets by a workshop angle meter with 15' precision. Generally, no higher than $\pm 0,5^{\circ}$ average deviation was recorded for all materials and geometries.

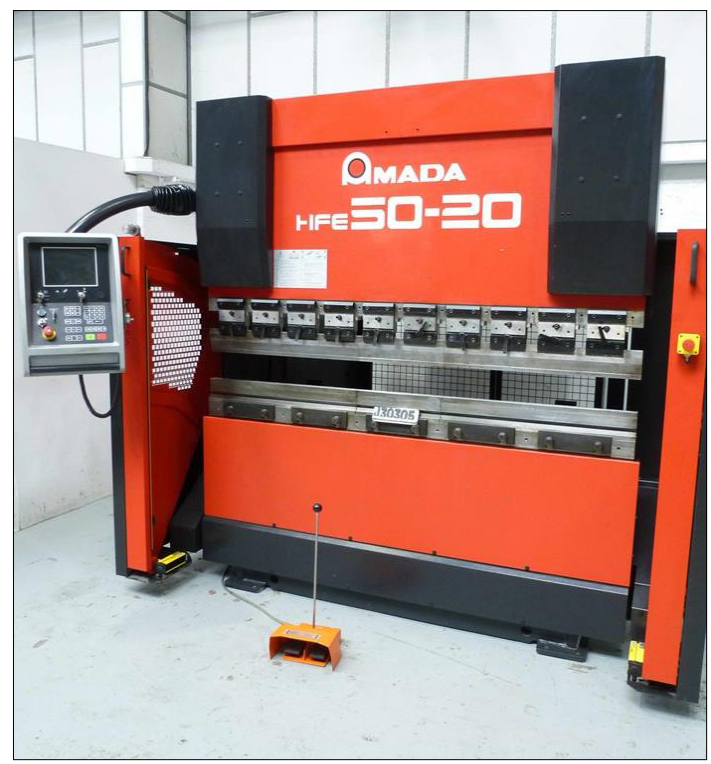

Figure 2. The applied Amada bending machine.

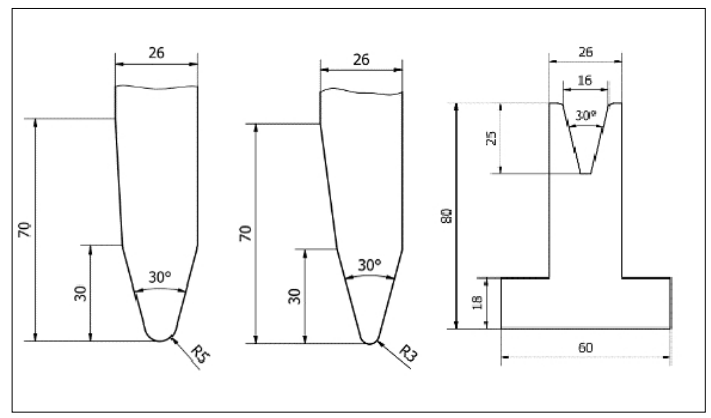

Figure 3. The applied punch and die geometry. 


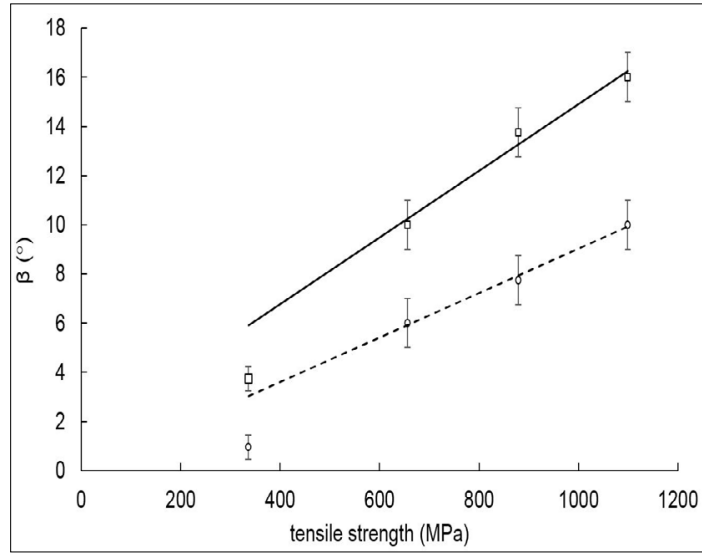

Figure 4. The experimental spring-back angles of the base materials.

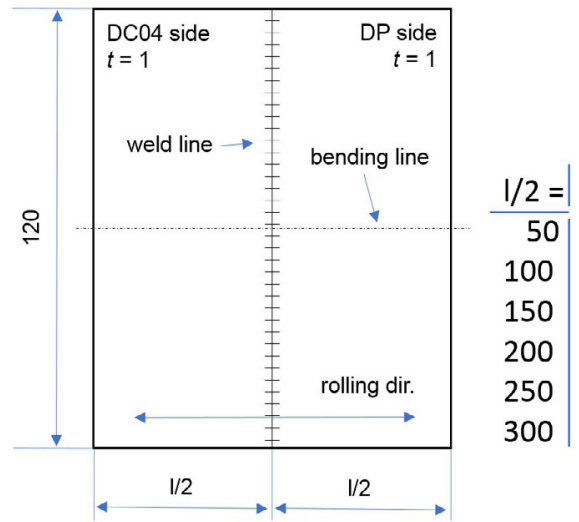

Figure 5. Schematic drawing of the TWB samples. Units in (mm).

The base materials had $120 \mathrm{~mm}$ width and $600 \mathrm{~mm}$ length, in which the length direction coincided with the rolling direction. The bending line was always perpendicular to the rolling direction. From the results it can be seen that both the strength and the $r / t$ ratio increase the springback angle $(\beta)$.

In case of the tailor welded blanks, all samples contained a DP steel grade coupled with the DC04 steel. This means that the DP side was changed from part to part, but the DC04 was constantly used. The blanks were created by laser beam welding at the Zoltán Bay Applied Research Nonprofit Ltd. The detailed characterization of the weld can be found in [10]. The aim of the experiments was to monitor the interaction between the different sides of the welded blank. The springback measurements were carried out on samples

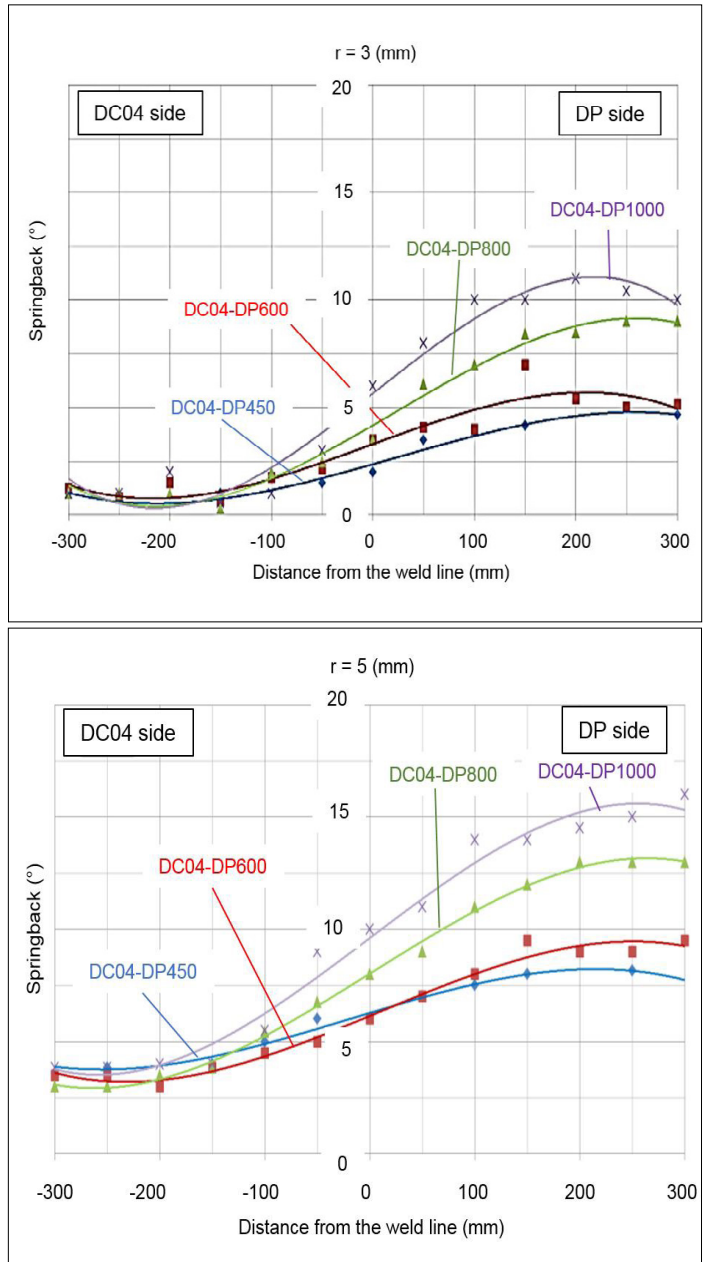

Figure 6. Experimental springback angels of TWBs.

with different lengths to make the welded zone's effect visible, in the function of the distance from the weld line. The schematic view of the welded sample design can be seen in Figure 5.

Figure6. shows the average experimental springback tendency of the tailor welded blanks. The final angles after elastic unloading were measured at the edges of the workpieces, i.e. at different distances from the weld line. The measurement method was equal to that applied at the base materials. According to the diagrams, none of the components show their characteristic springback value near to the weld line, rather a transition zone is developed.

It is noteworthy that the distinct spring-back angles within a work-piece actually create a shape error. 


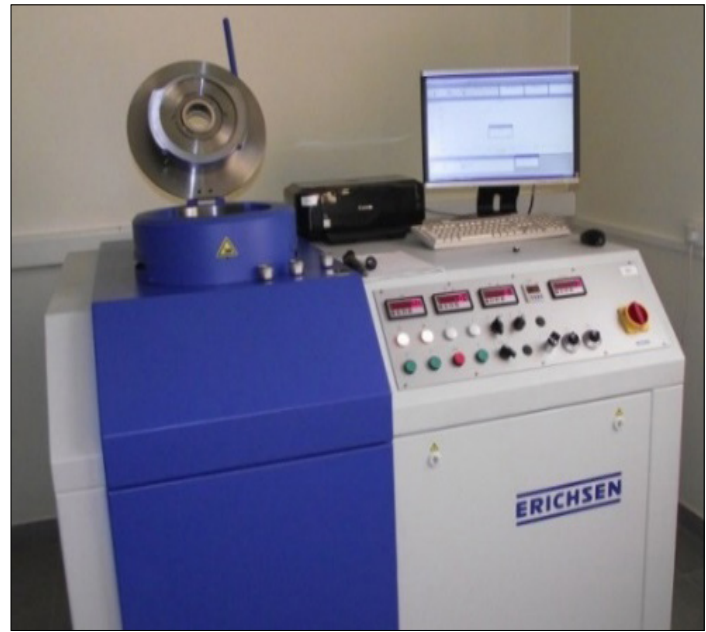

Figure 7. The applied universal sheet metal tester equipment.

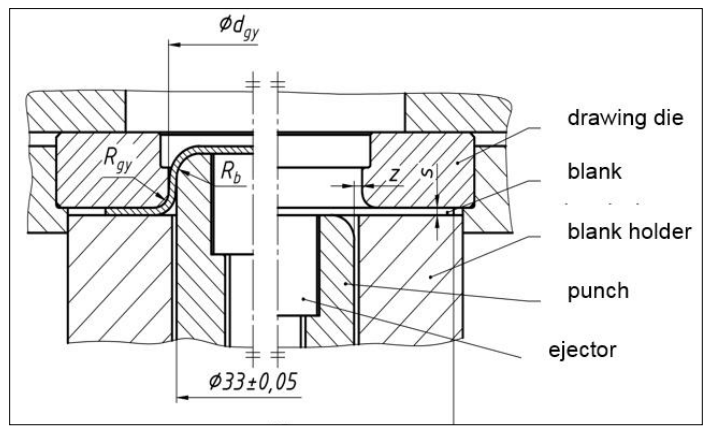

Figure 8. Schematic illustration of the deep-drawing tools.

\section{Experimental results of deep-drawability}

The deep-drawing tests of both the base and the welded materials were carried out by an Erichsen 142-20 universal sheet metal tester (Figure 7). The tooling was matched with the Swift cup drawing test's [11] tools, in accordance with the MSZ 573168 standard. The arrangement of the blank and the tools are depicted schematically in Figure 8.

In this testing method, the diameter of the blank $(D)$ is increased in $2 \mathrm{~mm}$ increments until crack occurrence. The circular blanks with $56,58,60, \ldots$ $80 \mathrm{~mm}$ diameter were manufactured by blanking and then turning with at least $\pm 0.1 \mathrm{~mm}$ precision. Three parallel measurements were performed in this case as well, with $0.012 \mathrm{~g} / \mathrm{cm}^{2}$ oil lubricant on the die side (as suggested by [12]) and with the optimal blank holder forces according to Siebel [13]). A sequence of DC04 deep-drawn cups can be seen in Figure 9 .

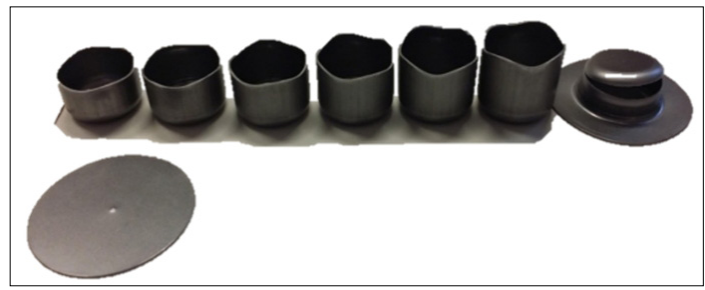

Figure 9. The sequence of drawn cups, DC04 material.

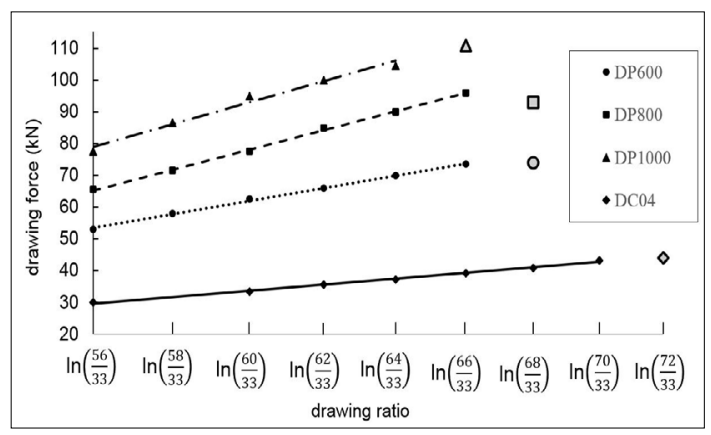

Figure 10. The limited drawing ratios and the corresponding drawing forces of the different base materials.

The average values of the biggest diameters, that could be drawn without failure (dashed mark) and the corresponding drawing forces are shown in Figure 10. It can be concluded that the increase in strength causes a decrease in the limited drawing ratio as well as an increase in the drawing force.

It is not necessary to explain in detail that the deep-drawing operation is accompanied by the most complicated stress and strain state in sheet metal forming. It is especially true for the welded blanks due to the inhomogeneous deformation of each segment and the different optimal blank holder forces of each side. However, the lower strength component has higher resistance to thinning (see Figure 10), its load carrying capacity is questionable if the drawing force is dictated by the higher strength part.

Workpiece manufacturing from the welded blanks is shown schematically in Figure 11. The mean measurement results are added in Figure 12. As a conclusion of the previous line of thought, it can be seen that the deep-drawability is neither influenced directly by the lower, nor the higher strength component, but is instead determined by the strength difference between each part. 


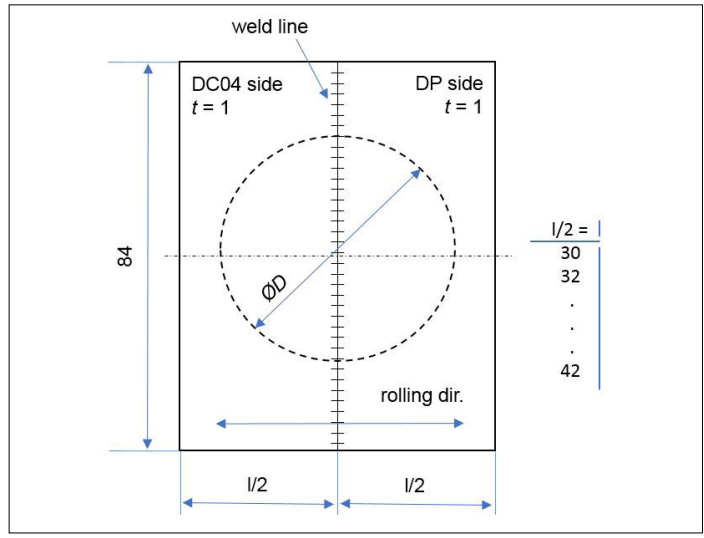

Figure 11. Schematic drawing of the welded specimens for the deep-drawing experiments.

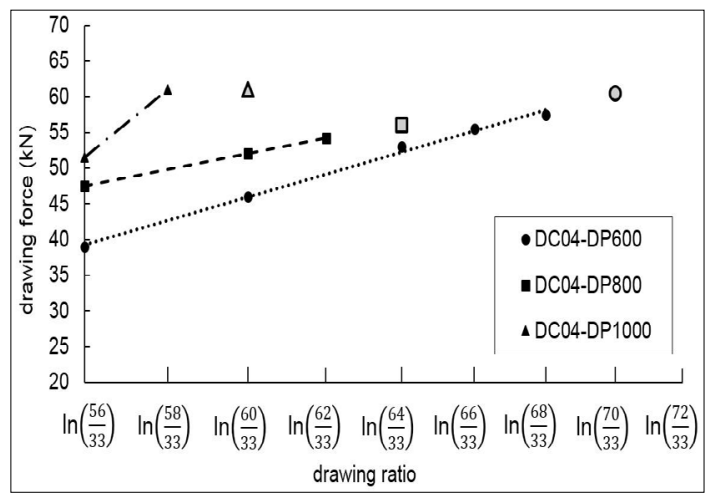

Figure 12. Experimental drawability results of the TWBs.

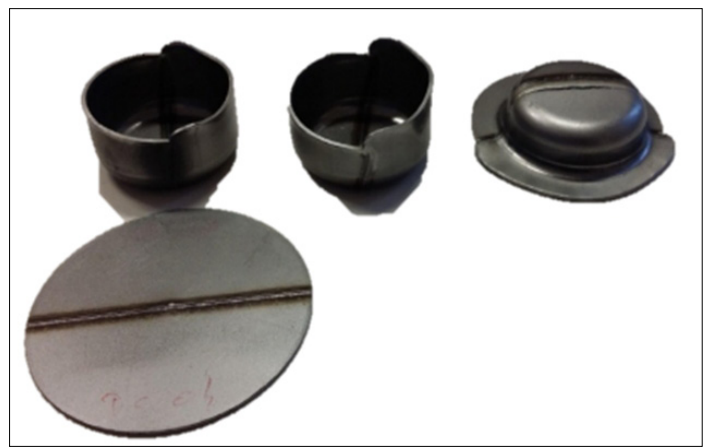

Figure 13. Picture of cups made by TWBs.

In contrast to the base materials, the drawability limit of the TWBs is restricted by the crack occurrence next to the weld line at the lower strength side, instead the cracking at the punch corner radius. It can be monitored in the pictures of the cups made by DC04-DP1000 TWBs (Figure 13.) that the lower strength side had stronger defor- mation thus earlier thinning occurred as well, due to the coercive effect of the higher strength component.

\section{Conclusion}

In this study we focused on the springback and deep-drawability behavior of three types of advanced high strength steels (DP600, DP800 and DP1000) and tailor welded blanks consisting the same materials extended by a cold-rolled, mild steel, DC04. Our results show that springback is increased with the strength of the applied material on its own. However, using tailor welded blanks, springback is developed especially in a transition zone, in which the final angle differs from both components' characteristic values. In the field of deep-drawability it is shown that the higher the strength the lower the limited drawing ratio for the base materials. In the case of the tailor welded blanks, it is not the strength of the components but the strength difference between them that determines the maximum drawing ratio, i.e. the formability.

\section{References}

[1] Merklein M., Johannes M., Lechner M., Kuppert A.: A review on tailored blanks-Production, applications and evaluation. Journal of Materials Processing Technology, 214. (2014) 151-164. https://doi.org/10.1016/j.jmatprotec.2013.08.015

[2] Keeler S., Kimchi M.: Advanced High-Strength Steels Application Guidelines Version 6.0. 3S-Superior Stamping Solutions. LLC., WorldAutoSteel, 2017. 1-17.

[3] Kuziak R., Kawalla R., Waengler S.: Advanced high strength steels for automotive industry. Archives of Civil and Mechanical Engineering, 8/2. (2008) 103-117. https://doi.org/10.1016/S1644-9665(12)60197-6

[4] Thyssenkrupp: Deep-drawing steels DD, DC and DX. Production information, 2018. 2-9.

[5] Danyi J., Végvári F.: Lemezmegmunkálás. Kecskeméti Főiskola, $1^{\text {st }}$ ed., Kecskemét, 2011. 97-104.

[6] Marciniak Z., Duncan J. L., Hu S. J.: Mechanics of Sheet Metal Forming. Butterworth-Heinemann, Oxford, 2002. 82-107.

[7] Lange K.: Handbook of Metal Forming. SME, Dearborn: Michigan, 1985. 19.1-19.23.

[8] Pearce R.: Sheet metal forming. Adam Hilger Series on new manufacturing processes and materials. IOP Publising Ltd., 1991. 79-88.

[9] Metals Handbook Vol. 4. Forming. $8^{\text {th }}$ ed. American Society for Metals, Ohio: Metals Park, 1969.

[10] Kovács Zs. F., Béres G., Weltsch Z.: Autóipari DC és DP acélok lézersugaras hegeszthetöségének vizsgálata. Gradus, 4 (2017) 311-317. 
[11] Swift, H. W.: Drawing tests for sheet metal. Proceedings Institution of Automobile Engineers, 34:361 (1939)

[12] Siebel E., Beisswanger H.: Deep Drawing. Carl Hanser, München, 1955.

[13] Altan T., Tekkaya A. E.: Sheet Metal Forming Fundamentals. ASM International, 2012. 105-127. 